\title{
Roles of long non-coding RNA in osteoarthritis (Review)
}

\author{
JICHENG WANG, YANSHAN SUN, JIANYONG LIU, BO YANG, TENGYUN WANG, \\ ZHEN ZHANG, XIN JIANG, YONGZHI GUO and YANGYANG ZHANG
}

Department of Joint Surgery, Weifang People's Hospital, Weifang, Shandong 261000, P.R. China

Received January 31, 2021; Accepted May 5, 2021

DOI: $10.3892 / \mathrm{ijmm} .2021 .4966$

\begin{abstract}
Osteoarthritis (OA) is a chronic bone and joint disease characterized by articular cartilage degeneration and joint inflammation and is the most common form of arthritis. The clinical manifestations of OA are chronic pain and joint activity disorder, which severely affect the patient quality of life. Long non-coding RNA (lncRNA) is a class of RNA molecules $>200$ nucleotides long that are expressed in animals, plants, yeast, prokaryotes and viruses. IncRNA molecules lack an open reading frame and are not translated into protein. The present review collated the results of recent studies on the role of IncRNA in the pathogenesis of OA to provide information for the prevention, diagnosis and treatment of OA.
\end{abstract}

\section{Contents}

1. Introduction

2. Biological functions of lncRNA

3. Relationship between IncRNAs and osteoarthritis

4. Conclusions and perspectives

\section{Introduction}

Osteoarthritis (OA) is a chronic bone and joint disease characterized by articular cartilage degeneration and joint inflammation (1). OA is the most common form of arthritis, and the main clinical manifestations of OA are chronic pain and joint activity disorder (1), which severely affect quality of life. OA is most common in middle-aged and elderly

Correspondence to: Professor Yangyang Zhang, Department of Joint Surgery, Weifang People's Hospital, 151 Guangwen Street, Kuiwen, Weifang, Shandong 261000, P.R. China

E-mail: zhangyy20212021@163.com

Abbreviations: ECM, extracellular matrix; lncRNA, long non-coding RNA; LPS, lipopolysaccharide; MB, methylene blue; miRNA, microRNA; OA, osteoarthritis; RBP, RNA-binding protein

Key words: chondrocytes, transcriptional regulation, lncRNAs, non-coding RNAs, osteoarthritis, synoviocytes individuals (2-3). The pathogenesis of OA is complex, and its etiology remains unclear. At present, the occurrence of $\mathrm{OA}$ is considered to be associated with various risk factors including mechanical, genetic and physical factors (4-6). A number of these factors, such as age, sex, obesity and bone density, increase the risk of OA; age has been reported to be an independent risk factor (4-6). The treatment of OA aims to alleviate or control pain, delay or prevent disease progression, improve or reconstruct joint function, correct deformity and ensure quality of life. OA treatment is based on the combination of disease education, sports activity guidance, drug and, if necessary, surgical treatment. In addition, an individualized treatment plan may be developed considering the patient's age, sex, location, OA extent, symptoms and underlying diseases. However, the clinical results obtained by conventional treatment are poor, and the risk of side effects is high (7). Therefore, elucidating the pathological mechanism of OA may be helpful in finding novel specific biomarkers that can contribute to the development of effective treatments for controlling the symptoms of OA.

The human genome is estimated to contain $\sim 2 \%$ protein-coding RNA, whereas the vast majority of the genome comprises non-protein-coding RNA $(8,9)$. According to their sequence length, non-coding RNA molecules are divided into two categories: i) Small non-coding RNAs, including microRNA (miRNA), ribosomal, small nucleolar, piwi-interacting and small interfering RNA; and ii) long non-coding RNA (lncRNA) (10-13). The latter category includes circular RNA, a class of lncRNA abundantly expressed and highly conserved in mammals (14) that are mainly derived from transcripts of exon or intron splicing (15).

IncRNA is a class of RNA molecules $>200$ nucleotides long expressed including animals, plants, yeast, prokaryotes and viruses $(16,17)$. lncRNAs lack an obvious open reading frame and do not serve the function of translation into protein (18). Numerous lncRNAs are named according to their host protein-coding gene. Based on the process through which they are generated from host protein-coding genes, IncRNAs are divided into five major classes: i) Long intergenic lncRNA, transcribed from intergenic regions; ii) intronic lncRNA, completely transcribed from introns; iii) sense lncRNA, transcribed from the sense strand of a protein-coding gene, including gene coding sequences of exons or introns; iv) antisense lncRNA, transcribed from the antisense strand of a protein-coding gene; and v) bidirectional lncRNA, transcribed in the opposite direction of 
the protein-coding gene and its exons (16). In humans, the synthesis of lncRNA is similar to that of mRNA; following splicing, it is modified by the addition of a 5' cap and 3 ' polyadenylation, resulting in the IncRNA obtaining transcriptional activation functions (19).

Previous studies have reported that the epigenetic effects of histone modification, DNA methylation and non-coding RNA may promote the pathological development of OA (20). lncRNAs can be used as diagnostic and therapeutic biomarkers for evaluating OA progression and prognosis $(21,22)$. The present review collated the findings of recent studies on the roles of IncRNA in the pathogenesis of OA to provide information for the prevention, diagnosis and treatment of OA.

\section{Biological functions of IncRNA}

lncRNAs function by regulating the epigenetic state of their proximal and distal protein-coding genes via cis- and trans-acting mechanisms $(23,24)$. IncRNAs mediate gene expression at the transcriptional, RNA processing and translational levels mainly by binding to chromatin-modifying complexes and acting as scaffolding modifiers, or by binding to transcription factors as transcriptional co-regulators $(23,24)$. IncRNAs control gene transcription in several manners: By regulating transcription factor combination and assembly (25); by forming three-chain complexes with regulatory sequences of protein-coding genes (26); and by binding to RNA polymerase II in order to interfere with the transcription process (27). In addition, IncRNAs control chromatin remodeling and histone modification, and also interact with miRNAs to participate in numerous biological processes, including embryonic development, cell growth, cell proliferation, cell cycle, gene transcription, splicing, translation, cell structure maintenance, chromatin remodeling, apoptosis, immune and heat shock responses (28-30). Deregulation of lncRNA expression may be involved in various types of cancer and inflammatory diseases $(31,32)$.

Chondrocytes are the only cells in the articular cartilage; extracellular matrix (ECM) degradation, chondrocyte apoptosis and cytokine production are crucial for the pathological progression of OA $(33,34)$. IncRNAs serve important roles in the development of bone and cartilage, and their abnormal expression in OA cartilage promotes the degradation of the cartilage ECM $(33,34)$. By contrast, modulation of lncRNAs may lead to the inhibition of ECM degradation, reduction in chondrocyte apoptosis and an inflammatory response that may delay the pathological progression of OA $(33,34)$.

\section{Relationship between IncRNAs and osteoarthritis}

Previous studies have reported that lncRNAs are involved in the development of numerous diseases, such as cancer, metabolic, cardiovascular, neurodegenerative and mental disorders $(35,36)$. However, the role of IncRNAs in the pathogenesis of OA is not well understood. In the OA cartilage tissue, certain IncRNAs are expressed at high levels, whereas others are expressed at low levels. Previous studies have reported that compared with healthy cartilage tissue, the expression levels of six lncRNAs [homeobox transcript antisense RNA (HOTAIR), growth arrest-specific transcript 5 (GAS5), PMS1 homolog 2 mismatch repair system component pseudogene 2 (PMS2P2), RP11-445H22.4, H19 and CTD-2574D22.4] are upregulated in OA cartilage, and this upregulation may serve a role in the pathogenesis of OA by increasing the mRNA expression levels of MMP9, MMP13, bone morphogenic protein 2 and the disintegrin and metalloproteinase with thrombospondin motifs 5 (ADAMTS5) (36). Another study has demonstrated that compared with healthy cartilage tissue, expression levels of the lncRNA maternal expression gene 3 (MEG3) are downregulated in OA cartilage, whereas vascular endothelial growth factor (VEGF) expression levels are upregulated, with a significant correlation between the two (37). VEGF has been reported to promote hypertrophic cartilage remodeling, ossification and vascular invasion of the cartilage-subchondral bone junction, thus serving an important role in the progression of OA (38). Taken together, these studies suggest that various lncRNAs may modulate the pathological progression of OA.

Metastasis-associated lung adenocarcinoma transcript 1 (MALAT1). MALAT1 is expressed in numerous tissues and is involved in certain diseases and biological processes; the expression of MALAT1 is upregulated in various types of cancer, such as lung cancer (39). Upregulation of MALAT1 promotes cell proliferation and inhibits apoptosis, whereas its downregulation inhibits cell proliferation and promotes apoptosis (39). A previous study has reported that MALAT1 is involved in the pathological process of OA, where its levels are upregulated together with AKT3 compared with those in healthy cartillage, whereas the levels of miR-150-5p are downregulated (40). This suggests that the expression levels of miR-150-5p is negatively associated with those of MALAT1 and AKT3. In addition, overexpression of MALAT1 inhibits the expression of miR-150-5p and promotes that of AKT3 (40). Overexpression of MALAT1 also reduces the expression of MMP13 and ADAMTS-5 and promotes the expression of type II collagen and aggrecan in chondrocytes treated with IL-1 $\beta$ (40). Furthermore, overexpression of MALAT1 inhibits apoptosis and ECM degradation, whereas the overexpression of miR-150-5p has the opposite effect; lncRNA MALAT1 has been reported to participate in OA via the miR-150-5p/AKT3 axis (40). Pan et al (41) have demonstrated that MALAT1 attenuates lipopolysaccharide (LPS)-induced inflammatory injury in ATDC5 cells by upregulating the levels of miR-19b and inhibiting the $\mathrm{Wnt} / \beta$-catenin and $\mathrm{NF}-\kappa \mathrm{B}$ pathways, and provides a potential target for the diagnosis and treatment of OA. Another study has reported that MALAT1 binds directly to miR-127-5p to inhibit its activity, increase the expression levels of osteopontin and promote chondrocyte proliferation via the PI3K/Akt pathway, which constitutes another target for the treatment of OA (42).

MEG3 lncRNA. A previous study has demonstrated a negative correlation between MEG3 lncRNA and VEGF levels in patients with OA (37). Li et al (43) have reported that Methylene blue $(\mathrm{MB})$ attenuates OA-related pain by upregulating the expression levels of MEG3 lncRNA, and that MEG3 inhibits $\mathrm{P} 2 \mathrm{X}$ purinoceptor 3 ( $\mathrm{P} 2 \mathrm{X} 3$ ) expression in a rabbit OA model and alleviates OA-related inflammation. Chen et al (44) have demonstrated that the levels of MEG3 are upregulated in OA compared with those in normal cartilage tissue, and that 
transforming growth factor- $\beta$ receptor type II (TGFBR2) is a direct target of miR-93 and is involved in the progression of OA; lncRNA MEG3 targets the miR-93/TGFBR2 axis, inhibits the degradation of cartilage ECM and delays the progression of OA (45). Another has reported that knockdown of MEG3 attenuates LPS-induced inflammatory damage in ATPS5 cells by modulating miR-203 expression (46). In addition, miR-203 stimulates Sirt1 expression, and Sirt1 mediates the PI3K/AKT and $\mathrm{NF}-\kappa \mathrm{B}$ pathways to attenuate LPS-induced inflammatory damage (46). Sirt1 is a key factor in the induction of OA, and the reduction of Sirt1 in chondrocytes may lead to chondrocyte hypertrophy and cartilage matrix loss (47). With the development of OA, the expression levels of Sirt1 are reduced, promoting the production of inflammatory factors (48). Additionally, $\mathrm{Xu}$ and $\mathrm{Xu}$ (49) have demonstrated that, in a rat OA model, silencing of MEG3 exerts antiproliferative and proapoptotic effects through the miR-16/SMAD7 axis, inhibits rat chondrocyte proliferation and promotes apoptosis.

HOTAIR. HOTAIR serves an important role in cancer progression, such as gastrointestinal stromal tumors, breast and pancreatic cancer (50). A previous study has demonstrated that HOTAIR is expressed in the human cartilage (36). In addition, the levels of $\alpha-1,2$ fucosyltransferase 2 (FUT2) are upregulated in OA compared with those in healthy cartilage tissue (51). Hu et al (52) have reported that HOTAIR and FUT2 are upregulated in OA cartilage compared with healthy cartilage tissue, aggravating ECM degradation and chondrocyte apoptosis and promoting OA progression through the Wnt/ $\beta$-catenin pathway. HOTAIR and ADAMTS-5 have also been reported to be upregulated in OA cartilage, aggravate ECM degradation and promote OA progression (53). Inhibition of HOTAIR expression may be a novel strategy for human OA therapy.

H19 $\operatorname{lncRNA}$. H19 is a maternal-expressed lncRNA that regulates the inflammatory response (54). Hu et al (54) have reported that H19 IncRNA is highly expressed in OA chondrocytes and aggravates LPS-induced C28/I2 cell injury by inhibiting miR-130a. Another study has confirmed that H19 lncRNA induces chondrocyte damage by promoting the expression of miR-675 (55), suggesting that H19 lncRNA acts on miRNAs to promote the progress of OA.

$X$-inactive-specific transcript (XIST) lncRNA. The lncRNA XIST is involved in the pathogenesis of various types of cancer, such as bladder cancer (56). A previous study has reported that XIST is upregulated in OA cartilage compared with healthy cartilage tissue (22). XIST acts as a competitive endogenous RNA of miR-1277-5p in OA, promoting the expression of MMP-13 and ADAMTS5 and degrading the ECM; downregulation of XIST protects the ECM (57). Previous studies have reported that a specific receptor for chemokine stromal cell-derived factor-1 termed C-X-C chemokine receptor 4 (CXCR4) serves a key role in cartilage damage and repair (58-61). XIST has also been demonstrated to promote the proliferation and apoptosis of OA chondrocytes via the miR-211/CXCR4 axis (62). Therefore, inhibition of XIST expression may delay OA progression.
FOXD2-adjacent opposite strand RNA 1 (FOXD2-AS1) $\ln c R N A$. A previous study has demonstrated that FOXD2-AS1 promotes the degradation of ECM (63). Toll-like receptors (TLRs) are pattern recognition receptors that are involved in the inflammatory process $(64,65)$, and TLR4 may serve a key role in the progression of OA (66). Wang et al (67) have reported that the levels of FOXD2-AS1 are upregulated in OA compared with those in healthy cartilage tissue, and overexpression of FOXD2-AS1 upregulates TLR4 expression levels via miR-27a-3p, inducing inflammation and ECM degradation, and promoting OA progression. Cyclin D1 (CCND1) is a regulator of OA progression, and CCND1 gene silencing has been demonstrated to promote IL- $1 \beta$-induced apoptosis in rat chondrocytes (68). Cao et al (69) have reported that FOXD2-AS1 knockdown significantly inhibits the expression of CCND1 at the mRNA and protein levels. Therefore, high expression levels of FOXD2-AS1 may promote the expression of CCND1 by inhibiting the expression of miR-206, promoting the viability of chondrocytes in OA, and FOXD2-AS1 may represent a potential target for the treatment of OA.

GAS5. GAS5 exerts a tumor-suppressive effect, which promotes apoptosis and inhibits the proliferation of various types of cancer cells, such as hepatocellular carcinoma and breast cancer (70-72). GAS5 expression levels are downregulated in $\mathrm{OA}$ chondrocytes compared with those in healthy cartilage tissue, and overexpression of GAS5 may ameliorate LPS-induced inflammatory damage in ATPS5 chondrocytes by inhibiting the NF- $\mathrm{B}$ and Notch signaling pathways. Kruppel-like factor 2 is the target of GAS5 (73). However, another study has demonstrated that GAS5 levels are upregulated in OA chondrocytes,compared with those in healthy cartilage tissue, and that it increases the expression of MMPs, stimulates apoptosis and inhibits autophagy (74). GAS5 participates in the pathogenesis of OA by negatively regulating miR-21 (74). Therefore, the specific mechanism of GAS5 in OA pathological processes require further study.

Cartilage injury-related (CIR) lncRNA. The lncRNA CIR is associated with ECM degradation and serves a key role in the pathogenesis of OA (21). Dysregulation of autophagy-related gene expression is involved in the pathogenesis of OA (75-77). Wang et al (78) have demonstrated that CIR is highly expressed in OA and increases MMP-3 expression levels by activating autophagy, reduces the levels of collagen type II $\alpha 1$ and promotes OA progression. Another study has confirmed that CIR is significantly upregulated in patients with OA compared with healthy subjects, and that overexpression of CIR increases the expression levels of MMP-13, whereas miR-27 inhibits the expression of MMP-13 (79). These changes can be detected in the target tissue or serum. CIR is involved in the degradation of ECM in OA chondrocytes via the CIR/miR-27/MMP-13 axis (79). Therefore, CIR may represent a novel target for the treatment of OA.

Differentiation antagonizing non-protein coding $R N A$ (DANCR). A previous study has demonstrated that DANCR promotes human mesenchymal stem cell proliferation and chondrogenic differentiation by upregulating the expression of Smad3 and STAT3 (80). A recent study has reported that 
DANCR promotes the proliferation of OA chondrocytes and inhibits apoptosis by regulating the miR-216a-5p/JAK2/STAT3 signaling pathway; DANCR may be a useful biomarker and a potential therapeutic target for OA (81). Zhang et al (80) have also demonstrated that DANCR activates cartilage formation in synovium-derived mesenchymal stem cells by upregulating Smad3 and STAT3. Sphingosine kinase (SPHK) is the major limiting enzyme for sphingoid-based phosphate synthesis in cells and has two isotypes, Sphk1 and SphK2. SPHK2 can promote apoptosis and inhibit cell proliferation $(82,83)$. A previous study has demonstrated that DANCR may promote OA chondrocyte proliferation and reduce apoptosis through the miR-577/SPHK2 axis (84), suggesting that DANCR lncRNA may be a potential therapeutic target for OA.

Other IncRNAs. Myocardial infarction-associated transcript (MIAT), also termed retinal non-coding RNA 2 or Gomafu, is a functional lncRNA associated with the risk of myocardial infarction (85) that is involved in numerous diseases, such as neurological diseases (86), neovascularization disease (87) and cancer, such as neuroendocrine prostate cancer (88). MIAT has been reported to be involved in the inflammatory response in diseases such as myocardial infarction, schizophrenia, ischemic stroke, diabetes complications, age-related cataract and cancer (89). miR-132 is one of the miRNAs that regulate chondrogenic differentiation (90); a previous study has demonstrated that miR-132 is a downstream effector of MIAT, through which MIAT exerts its biological functions (91). A recent study has reported that silencing MIAT protects ATDC5 cells from LPS-induced damage, potentially by upregulating the expression levels of miR-132 and inhibiting the NF- $\kappa \mathrm{B}$ and JNK pathways (92).

The plasmacytoma variant translocation 1 (PVT1) lncRNA is located at human $8 \mathrm{q} 24.21$ and is dysregulated in various diseases, such as OA (36). The levels of PVT1 are upregulated in patients with OA compared those in healthy subjects (36). A recent study has demonstrated that PVT1 lncRNA directly binds to miR-149 to inhibit its expression and activity. Overexpression of PVT1 lncRNA promotes OA progression by aggravating cartilage imbalance, leading to catabolism and an inflammatory response (93). Li et al (94) have reported that the expression levels of PVT1 lncRNA are upregulated in $\mathrm{OA}$ chondrocytes compared with those in healthy cartilage tissue, whereas its overexpression promotes normal chondrocyte apoptosis. Further experiments have revealed that PVT1 lncRNA regulates chondrocyte apoptosis by sponging miR-488-3p in OA.

lncRNA PTGS2 antisense NFKB1 complex-mediated expression regulator RNA (PACER) is associated with chondrocyte inflammation, which contributes to OA (38). A previous study has demonstrated that the levels of PACER are downregulated in OA compared with those in healthy cartilage tissue, whereas the levels of HOTAIR are upregulated, and PACER overexpression inhibits chondrocyte apoptosis by downregulating the levels of HOTAIR, thus delaying OA (95). Cancer susceptibility 2 (CASC2) lncRNA is a tumor suppressor that inhibits cell proliferation and promotes apoptosis $(96,97)$. A previous study has reported that the expression levels of CASC2 IncRNA are upregulated in the plasma of patients with OA compared with those in healthy subjects; overexpression of CASC2 lncRNA leads to the upregulation of IL-17 expression levels in CHON-001 human chondrocytes, inhibition of cell proliferation and increased chondrocyte apoptosis (98). Chu et al (99) have reported that the highly upregulated in liver cancer (HULC) IncRNA protects ATDC5 cells from TNF- $\alpha$-induced inflammatory damage by inhibiting miR-101 and blocking the NF- $\mathrm{NB}$ and MAPK signaling pathways. Therefore, HULC IncRNA may be used as a therapeutic agent for OA.

lncRNA activated by transforming growth factor- $\beta$ (lncRNA-ATB) is a cancer-associated lncRNA $(100,101)$. MyD88 is a key adaptor of the TLR4 signaling pathway and initiates the transduction of downstream inflammatory factors, such as TLRs (100). IncRNA-ATB downregulates the expression levels of miR-223 and inhibits the MyD88/NF- $\kappa \mathrm{B}$ and $\mathrm{p} 38$ MAPK pathways to protect ATDC5 cells from LPS-induced inflammatory injury (101). The expression levels of the oncogene taurine upregulated gene 1 (TUG1) are associated with a poor prognosis in OA. Tang et al (102) have demonstrated that TUG1 lncRNA overexpression inhibits the expression of miR-195, collagen and aggrecan, increases the expression of levels of MMP13 and promotes ECM degradation in OA. Induced myeloid leukemia cell differentiation protein (MCL1) is an antiapoptotic member of the Bcl-2 family of proteins and is a key regulator of chondrocyte death (103). Li et al (104) have reported that PMS2L2 increases cell viability, reduces apoptosis and inhibits the release of pro-inflammatory factors in ATDC5 cells exposed to LPS; in addition, PMS2L2 acts through the PMS2L2/miR-203/MCL1 axis, which may provide a novel gene therapy strategy for OA. MB enhances the key biochemical pathways in the mitochondria and may hinder oxidant production (105); MB has been demonstrated to inhibit the degradation of chondrocytes in OA by targeting chondrocyte inflammation-associated lincRNA02 in order to regulate the expression levels of tissue inhibitor of metalloproteinase-1 and MMPs (106). TNF and hnRNPL-associated immunoregulatory lincRNA (THRIL) serves a key role in the regulation of TNF expression and inflammation through interaction with hnRNPL (107). Liu et al (108) have demonstrated that overexpression of THRIL downregulates the levels of miR-125b and activates the JAK1/STAT3 and NF- $\mathrm{kB}$ pathways to promote LPS-induced inflammatory injury in ATDC5 cells. A recent study has reported that the expression levels of the antisense strand of intron 1 of Fas gene (FAS-AS1) are increased in OA compared with those in healthy cartilage tissue; FAS-AS1 lncRNA is involved in the development of OA by inhibiting the proliferation of chondrocytes, promoting apoptosis and the degradation of ECM (63).

Recent studies have reported that 384 mRNAs and 17 lncRNAs are differentially expressed in the OA compared with healthy synovium (109). These differentially expressed lncRNAs may serve key roles in OA synovitis and provide a reference for OA diagnosis (109). Another study has suggested that exogenous prostate cancer gene expression marker 1 lncRNA may be a suitable indicator for distinguishing between early and advanced OA (110). Taken together, these studies suggest that the functional genetic variation of lncRNAs serves an important role in the pathogenesis of OA. The targets and functions of various lncRNAs involved in OA are summarized in Table I. 
Table I. Biological functions of lncRNAs in osteoarthritis.

\begin{tabular}{|c|c|c|c|c|}
\hline lncRNA & Target & Signaling pathway/axis & Function & (Refs.) \\
\hline MALAT1 & $\begin{array}{l}\operatorname{miR}-150-5 p \\
\operatorname{miR}-19 b \\
\operatorname{miR}-127-5 p\end{array}$ & $\begin{array}{l}\text { Akt } \\
\text { Wnt/ } \beta \text {-catenin, NF- } \kappa B \\
\text { PI3K/Akt }\end{array}$ & $\begin{array}{l}\text { Increase in cell proliferation, inhibition } \\
\text { of apoptosis, ECM degradation and } \\
\text { inflammation }\end{array}$ & $(40-42)$ \\
\hline MEG3 & $\begin{array}{l}\text { P2X3 } \\
\text { miR-93 } \\
\text { miR-203 } \\
\text { miR-16 }\end{array}$ & $\begin{array}{l}\text { P2X3 } \\
\text { miR-93/TGFBR2 } \\
\text { PI3K/AKT, NF-кB B } \\
\text { miR-16/SMAD7 }\end{array}$ & $\begin{array}{l}\text { Increase in cell proliferation, inhibition } \\
\text { of apoptosis, ECM degradation and } \\
\text { inflammation, pain relief }\end{array}$ & $(43-46,49)$ \\
\hline HOTAIR & $\begin{array}{l}\text { FUT2 } \\
\text { ADAMTS }\end{array}$ & Wnt/ $\beta$-catenin & Increase in apoptosis, ECM degradation & $(52,53)$ \\
\hline H19 & $\begin{array}{l}\operatorname{miR}-130 a \\
\operatorname{miR}-675\end{array}$ & PI3K/Akt & $\begin{array}{l}\text { Aggravation of inflammatory response, } \\
\text { induction of chondrocyte injury }\end{array}$ & $(54,55)$ \\
\hline XIST & $\begin{array}{l}\operatorname{miR}-1277-5 p \\
\operatorname{miR}-211\end{array}$ & $\begin{array}{l}\mathrm{miR}-1277-5 \mathrm{p} / \mathrm{ADAMTS} 5 \\
\mathrm{miR}-211 / \mathrm{CXCR} 4\end{array}$ & ECM degradation, increase in apoptosis & $(57,62)$ \\
\hline FOXD2-AS1 & $\begin{array}{l}\operatorname{miR}-27 a-3 p \\
\operatorname{miR}-206\end{array}$ & $\begin{array}{l}\operatorname{miR}-27 \mathrm{a}-3 \mathrm{p} / \mathrm{TLR} 4 \\
\mathrm{miR}-206 / \text { cyclin D1 }\end{array}$ & ECM degradation, induction of inflammation & $(67,69)$ \\
\hline GAS5 & $\begin{array}{l}\text { KLF2 } \\
\text { miR-21 }\end{array}$ & $\begin{array}{l}\text { NF- } \kappa \text { B, Notch } \\
\text { miR-21/MMPs }\end{array}$ & $\begin{array}{l}\text { Reduction in inflammation, induction of } \\
\text { apoptosis, inhibition of autophagy }\end{array}$ & $(73,74)$ \\
\hline CIR & $\begin{array}{l}\text { LC3II, beclin-1 } \\
\operatorname{miR}-27 \mathrm{~b}\end{array}$ & $\begin{array}{l}\text { Autophagy signaling } \\
\text { miR-27b/MMP13 }\end{array}$ & Activation of autophagy, ECM degradation & $(78,79)$ \\
\hline DANCR & $\begin{array}{l}\operatorname{miR}-216 a-5 p \\
\text { Myc } \\
\operatorname{miR}-577\end{array}$ & $\begin{array}{l}\text { miR-216a-5p/JAK2/STAT3 } \\
\text { Myc/SMAD3/STAT3 } \\
\text { miR-577/SPHK2 }\end{array}$ & $\begin{array}{l}\text { Increase in cell proliferation, inhibition of } \\
\text { apoptosis }\end{array}$ & $(80,81,84)$ \\
\hline MIAT & $\operatorname{miR}-132$ & $\mathrm{NF}-\kappa \mathrm{B}, \mathrm{JNK}$ & Increase in inflammatory responses & $(92)$ \\
\hline PVT1 & $\begin{array}{l}\operatorname{miR}-149 \\
\operatorname{miR}-488-3 p\end{array}$ & PI3K/Akt & $\begin{array}{l}\text { Increase in inflammatory responses, } \\
\text { apoptosis and catabolism }\end{array}$ & $(93,94)$ \\
\hline HULC & miR-101 & $\mathrm{NF}-\kappa \mathrm{B}, \mathrm{MAPK}$ & Reduction in inflammation & $(99)$ \\
\hline ATB & $\operatorname{miR}-223$ & MyD88/NF-кB, p38MAPK & Reduction in inflammation & $(101)$ \\
\hline TUG1 & miR-195 & miR-195/MMP-13 & ECM degradation & $(102)$ \\
\hline PMS2L2 & $\operatorname{miR}-203$ & miR-203/MCL-1 & $\begin{array}{l}\text { Increase in cell viability, reduction in } \\
\text { apoptosis and inflammation }\end{array}$ & $(104)$ \\
\hline THRIL & $\operatorname{miR}-125 b$ & JAK1/STAT3, NF-кB & Increase in inflammatory responses & $(108)$ \\
\hline FAS-AS1 & MMP1, MMP13 & PI3K/Akt & $\begin{array}{l}\text { Increase in cell proliferation and apoptosis, } \\
\text { ECM degradation }\end{array}$ & $(63)$ \\
\hline
\end{tabular}

lncRNA, long non-coding RNA; MALAT1, Metastasis-associated lung adenocarcinoma transcript 1; MEG3, maternal expression gene 3; HOTAIR, homeobox transcript antisense RNA; XIST, X-inactive-specific transcript; FOXD2-AS1, FOXD2-adjacent opposite strand RNA 1; GAS5, growth arrest-specific transcript 5; CIR, cartilage injury-related; DANCR, differentiation antagonizing non-protein coding RNA; MIAT, myocardial infarction-associated transcript; PVT1, plasmacytoma variant translocation 1; HULC, highly upregulated in liver cancer; ATB, transforming growth factor- $\beta$; TUG1, taurine-upregulated gene 1; PMS2L2, PMS1 homolog 2 mismatch repair system component pseudogene 2; THRIL, TNF and hnRNPL-associated immunoregulatory long intergenic non-coding RNA; FAS-AS1, antisense strand of intron 1 of Fas gene; miR, microRNA; P2X3, P2X purinoceptor 3; FUT2, $\alpha-1$, 2 fucosyltransferase 2; KLF2, ADAMTS, disintegrin and metalloproteinase with thrombospondin motifs; Kruppel-like factor 2; TGFBR2, TGF- $\beta$ receptor type II; CXCR4, C-X-C chemokine receptor 4; TLR4, Toll-like receptor 4; SPHK2, sphingosine kinase 2; MCL-1, induced myeloid leukemia cell differentiation protein; ECM, extracellular matrix.

\section{Conclusions and perspectives}

OA is one of the most common degenerative joint diseases, and pain that leads to restriction of physical activity is the main symptom. OA seriously affects quality of life and inflicts a heavy economic burden on families and society. Despite numerous studies on OA, its pathogenesis is still not fully understood, and it cannot be completely cured. The role of lncRNAs in the pathogenesis of OA has attracted increasing attention from scientists, as differentially expressed lncRNAs may provide new directions for the diagnosis and treatment of OA.

Various signaling pathways are involved in the pathological process of OA. Since lncRNAs serve a wide range of roles in biology, the majority of their targets are often essential cell signaling molecules. Identification of novel lncRNA-related pathway molecules may help to gain a deeper understanding of the role of IncRNAs in OA and provide a theoretical basis for targeted therapy. 
The present review represents a resource that described the important roles of lncRNAs in the pathogenesis of OA and reveals the interaction of IncRNAs, miRNAs and OA. Overall, this interaction suggests a potential role of lncRNAs in cell signaling and OA pathogenesis. Although previous studies have demonstrated the therapeutic effects of IncRNAs in OA, further research is needed to focus on the potential for the widespread use of lncRNAs as biomarkers in the diagnosis of OA and to develop novel therapeutic targets for OA. For example, a certain lncRNA molecule administered as a capsule or other type of medicine orally or via local injection, the lncRNA target may promote the proliferation of chondrocytes, inhibit ECM degradation, reduce the inflammatory response and alleviate the progress of OA. The ultimate goal is to use these targets to develop new drugs, delay the progress of OA and improve the patient quality of life.

\section{Acknowledgements}

Not applicable.

\section{Funding}

No funding was received.

\section{Availability of data and materials}

Not applicable.

\section{Authors' contributions}

JW and YZ drafted the manuscript and revised the manuscript. YS, JL, BY, TW, ZZ, XJ and YG contributed to manuscript conception. All authors have read and approved the final manuscript. Data authentication is not applicable.

\section{Ethics approval and consent to participate}

Not applicable.

\section{Patient consent for publication}

Not applicable.

\section{Competing interests}

The authors declare that they have no competing interests.

\section{References}

1. Taruc-Uy RL and Lynch SA: Diagnosis and treatment of osteoarthritis. Prim Care 40: 821-836, 2013.

2. Felson DT, Naimark A, Anderson J, Kazis L, Castelli W and Meenan RF: The prevalence of knee osteoarthritis in the elderly. The framingham osteoarthritis study. Arthritis Rheum 30: 914-918, 1987.

3. Oliveria SA, Felson DT, Reed JI, Cirillo PA and Walker AM: Incidence of symptomatic hand, hip, and knee osteoarthritis among patients in a health maintenance organization. Arthritis Rheum 38: 1134-1141, 1995.

4. Prieto-Alhambra D, Judge A, Javaid MK, Cooper C, Diez-Perez A and Arden NK: Incidence and risk factors for clinically diagnosed knee, hip and hand osteoarthritis: Influences of age, gender and osteoarthritis affecting other joints. Ann Rheum Dis 73: $1659-1664,2014$
5. Murphy L, Schwartz TA, Helmick CG, Renner JB, Tudor G, Koch G, Dragomir A, Kalsbeek WD, Luta G and Jordan JM: Lifetime risk of symptomatic knee osteoarthritis. Arthritis Rheum 59: 1207-1213, 2008.

6. Zhang W: Risk factors of knee osteoarthritis-excellent evidence but little has been done. Osteoarthritis Cartilage 18: 1-2, 2010.

7. Glyn-Jones S, Palmer AJ, Agricola R, Price AJ, Vincent TL, Weinans H and Carr AJ: Osteoarthritis. Lancet 386: 376-387, 2015.

8. Su AI, Wiltshire T, Batalov S, Lapp H, Ching KA, Block D, Zhang J, Soden R, Hayakawa M, Kreiman G, et al: A gene atlas of the mouse and human protein-encoding transcriptomes. Proc Natl Acad Sci USA 101: 6062-6067, 2004.

9. Mattick JS and Makunin IV: Non-coding RNA. Hum Mol Genet 15 Spec No 1: R17-R29, 2006

10. Elling R, Chan J and Fitzgerald KA: Emerging role of long noncoding RNAs as regulators of innate immune cell development and inflammatory gene expression. Eur J Immunol 46: 504-512, 2016.

11. Lander ES, Linton LM, Birren B, Nusbaum C, Zody MC, Baldwin J, Devon K, Dewar K, Doyle M, FitzHugh W, et al: Initial sequencing and analysis of the human genome. Nature 409: 860-921, 2001.

12. Costa FF: Non-coding RNAs: New players in eukaryotic biology. Gene 357: 83-94, 2005.

13. Sosińska P, Mikuła-Pietrasik J and Książek K: The double-edged sword of long non-coding RNA: The role of human brain-specific BC200 RNA in translational control, neurodegenerative diseases, and cancer. Mutat Res Rev Mutat Res 766: 58-67, 2015.

14. Jeck WR and Sharpless NE: Detecting and characterizing circular RNAs. Nat Biotechnol 32: 453-461, 2014.

15. Memczak S, Jens M, Elefsinioti A, Torti F, Krueger J, Rybak A, Maier L, Mackowiak SD, Gregersen LH, Munschauer M, et al: Circular RNAs are a large class of animal RNAs with regulatory potency. Nature 495: 333-338, 2013.

16. Ma L, Bajic VB and Zhang Z: On the classification of long non-coding RNAs. RNA Biol 10: 925-933, 2013.

17. Guo X, Gao L, Liao Q, Xiao H, Ma X, Yang X, Luo H, Zhao G, $\mathrm{Bu} \mathrm{D}$, Jiao $\mathrm{F}$, et al: Long non-coding RNAs function annotation: A global prediction method based on bi-colored networks. Nucleic Acids Res 41: e35, 2013.

18. Mercer TR, Dinger ME and Mattick JS: Long non-coding RNAs: Insights into functions. Nat Rev Genet 10: 155-159, 2009.

19. Fitzgerald KA and Caffrey DR: Long noncoding RNAs in innate and adaptive immunity. Curr Opin Immunol 26: 140-146, 2014.

20. Reynard LN and Loughlin J: Genetics and epigenetics of osteoarthritis. Maturitas 71: 200-204, 2012.

21. Liu Q, Zhang X, Dai L, Hu X, Zhu J, Li L, Zhou C and Ao Y: Long noncoding RNA related to cartilage injury pro-motes chondrocyte extracellular matrix degradation in osteoarthritis. Arthritis Rheumatol 66: 969-978, 2014.

22. Fu M, Huang G, Zhang Z, Liu J, Zhang Z, Huang Z, Yu B and Meng F: Expression profile of long noncoding RNAs in cartilage from knee osteoarthritis patients. Osteoarthritis Cartilage 23: 423-432, 2015

23. Rinn JL and Chang HY: Genome regulation by long noncoding RNAs. Annu Rev Biochem 81: 145-166, 2012.

24. Ulitsky I and Bartel DP: LincRNAs: Genomics, evolution, and mechanisms. Cell 154: 26-46, 2013.

25. Feng J, Bi C, Clark BS, Mady R, Shah P and Kohtz JD: The Evf-2 noncoding RNA is transcribed from the Dlx-5/6 ultraconserved region and functions as a Dlx-2 transcriptional coactivator. Genes Dev 20: 1470-1484, 2006.

26. Ohno M, Fukagawa T, Lee JS and Ikemura T: Triplex-forming DNAs in the human interphase nucleus visualized in situ by polypurine/polypyrimidine DNA probes and antitriplex antibodies. Chromosoma 111: 201-213, 2002.

27. Smart F, Aschrafi A, Atkins A, Owens GC, Pilotte J, Cunningham BA and Vanderklish PW: Two isoforms of the cold-inducible mRNA-binding protein RBM3 localize to dendrites and promote translation. J Neurochem 101: 1367-1379, 2007.

28. Krol J, Loedige I and Filipowicz W: The widespread regulation of microRNA biogenesis, function and decay. Nat Rev Genet 11: 597-610, 2010

29. Paraskevopoulou MD and Hatzigeorgiou AG: Analyzing MiRNA-LncRNA interactions. Methods Mol Biol 1402: 271-286, 2016.

30. Ponting CP, Oliver PL and Reik W: Evolution and functions of long noncoding RNAs. Cell 136: 629-641, 2009.

31. Gibb EA, Brown CJ and Lam WL: The functional role of long non-coding RNA in human carcinomas. Mol Cancer 10: 38, 2011. 
32. Marques-Rocha JL, Samblas M, Milagro FI, Bressan J, Martínez JA and Marti A: Noncoding RNAs, cytokines, and inflammation-related diseases. FASEB J 29: 3595-3611, 2015.

33. Aigner T, Söder S, Gebhard PM, McAlinden A and Haag J: Mechanisms of disease: Role of chondrocytes in the pathogenesis of osteoarthritis-structure, chaos and senescence. Nat Clin Pract Rheumatol 3: 391-399, 2007.

34. Le LT, Swingler TE and Clark IM: Review: The role of microRNAs in osteoarthritis and chondrogenesis. Arthritis Rheum 65: 1963-1974, 2013.

35. Jiang SD, Lu J, Deng ZH, Li YS and Lei GH: Long noncoding RNAs in osteoarthritis. Joint Bone Spine 84: 553-556, 2017.

36. Xing D, Liang JQ, Li Y, Lu J, Jia HB, Xu LY and Ma XL: Identification of long noncoding RNA associated with osteoarthritis in humans. Orthop Surg 6: 288-293, 2014

37. Su W, Xie W, Shang Q and Su B: The long noncoding RNA MEG3 is Downregulated and inversely associated with VEGF levels in osteoarthritis. Biomed Res Int 2015: 356893, 2015.

38. Pearson MJ, Philp AM, Heward JA, Roux BT, Walsh DA, Davis ET, Lindsay MA and Jones SW: Long intergenic noncoding RNAs mediate the human chondrocyte inflammatory response and are differentially expressed in osteoarthritis cartilage. Arthritis Rheumatol 68: 845-856, 2016.

39. Zhou Q, Tang X, Tian X, Tian J, Zhang Y, Ma J, Xu H and Wang S: LncRNA MALAT1 negatively regulates MDSCs in patients with lung cancer. J Cancer 9: 2436-2442, 2018.

40. Zhang Y, Wang F, Chen G, He R and Yang L: LncRNA MALAT1 promotes osteoarthritis by modulating miR-150-5p/AKT3 axis. Cell Biosci 9: 54, 2019.

41. Pan L, Liu D, Zhao L, Wang L, Xin M and Li X: Long noncoding RNA MALAT1 alleviates lipopolysaccharide-induced inflammatory injury by upregulating microRNA-19b in murine chondrogenic ATDC5 cells. J Cell Biochem 119: 10165-10175, 2018.

42. Liang J, Xu L, Zhou F, Liu AM, Ge HX, Chen YY and Tu M MALAT1/miR-127-5p regulates osteopontin (OPN)-Mediated proliferation of human chondrocytes through PI3K/Akt pathway. J Cell Biochem 119: 431-439, 2018.

43. Li X, Tang C, Wang J, Guo P, Wang C, Wang Y, Zhang Z and Wu H: Methylene blue relieves the development of osteoarthritis by upregulating lncRNA MEG3. Exp Ther Med 15: 3856-3864, 2018.

44. Chen K, Zhu H, Zheng MQ and Dong QR: LncRNA MEG3 inhibits the degradation of the extracellular matrix of chondrocytes in osteoarthritis via targeting miR-93/TGFBR2 axis Cartilage: Jun 28, 2019 (Epub ahead of print).

45. Zhou H, Wu G, Ma X, Xiao J, Yu G, Yang C, Xu N, Zhang B Zhou J, Ye Z and Wang Z: Attenuation of TGFBR2 expression and tumour progression in prostate cancer involve diverse hypoxia-regulated pathways. J Exp Clin Cancer Res 37: 89, 2018

46. Wang Z, Chi X, Liu L, Wang Y, Mei X, Yang Y and Jia T: Long noncoding RNA maternally expressed gene 3 knockdown alleviates lipopolysaccharide-induced inflammatory injury by up-regulation of miR-203 in ATDC5 cells. Biomed Pharmacother 100: 240-249, 2018.

47. Fujita N, Matsushita T, Ishida K, Kubo S, Matsumoto T, Takayama K, Kurosaka M and Kuroda R: Potential involvement of SIRT1 in the pathogenesis of osteoarthritis through the modulation of chondrocyte gene expressions. J Orthop Res 29: 511-515, 2011.

48. Niederer F, Ospelt C, Brentano F, Hottiger MO, Gay RE, Gay S, Detmar M and Kyburz D: SIRT1 overexpression in the rheumatoid arthritis synovium contributes to proinflammatory cytokine production and apoptosis resistance. Ann Rheum Dis 70: 1866-1873, 2011.

49. $\mathrm{Xu} \mathrm{J}$ and $\mathrm{Xu} \mathrm{Y}$ : The lncRNA MEG3 downregulation leads to osteoarthritis progression via miR-16/SMAD7 axis. Cell Biosci 7: 69, 2017.

50. Svoboda M, Slyskova J, Schneiderova M, Makovicky P, Bielik L, Levy M, Lipska L, Hemmelova B, Kala Z, Protivankova M, et al: HOTAIR long non-coding RNA is a negative prognostic factor not only in primary tumors, but also in the blood of colorectal cancer patients. Carcinogenesis 35: 1510-1515, 2014

51. Hu J, Wang Z, Pan Y, Ma J, Miao X, Qi X, Zhou H and Jia L: MiR-26a and miR-26b mediate osteoarthritis progression by targeting FUT4 via NF- $\kappa$ B signaling pathway. Int J Biochem Cell Biol 94: 79-88, 2018.

52. Hu J, Wang Z, Shan Y,Pan Y,Ma J and Jia L: Long non-coding RNA HOTAIR promotes osteoarthritis progression via miR-17-5p/ FUT2/ $\beta$-catenin axis. Cell Death Dis 9: 711, 2018
53. Dou P, Hu R, Zhu W, Tang Q, Li D, Li H and Wang W: Long non-coding RNA HOTAIR promotes expression of ADAMTS-5 in human osteoarthritic articular chondrocytes. Pharmazie 72 : 113-117, 2017

54. Hu Y, Li S and Zou Y: Knockdown of LncRNA H19 Relieves LPS-Induced damage by modulating miR-130a in osteoarthritis. Yonsei Med J 60: 381-388, 2019.

55. Steck E, Boeuf S, Gabler J, Werth N, Schnatzer P, Diederichs S and Richter W: Regulation of H19 and its encoded microRNA-675 in osteoarthritis and under anabolic and catabolic in vitro conditions. J Mol Med (Berl) 90: 1185-1195, 2012.

56. Hu Y, Deng C, Zhang H, Zhang J, Peng B and Hu C: Long non-coding RNA XIST promotes cell growth and metastasis through regulating miR- $139-5 \mathrm{p}$ mediated $\mathrm{Wnt} / \beta$-catenin signaling pathway in bladder cancer. Oncotarget 8: 94554-94568, 2017.

57. Wang T, Liu Y, Wang Y, Huang X, Zhao W and Zhao Z: Long non-coding RNA XIST promotes extracellular matrix degradation by functioning as a competing endogenous RNA of miR-1277-5p in osteoarthritis. Int J Mol Med 44: 630-642, 2019.

58. Pattoli MA, MacMaster JF, Gregor KR and Burke JR: Collagen and aggrecan degradation is blocked in interleukin-1-treated cartilage explants by an inhibitor of IkappaB kinase through suppression of metalloproteinase expression. J Pharmacol Exp Ther 315: 382-388, 2005.

59. Chen P, Tao J, Zhu S, Cai Y, Mao Q, Yu D, Dai J and Ouyang H: Radially oriented collagen scaffold with SDF-1 promotes osteochondral repair by facilitating cell homing. Biomaterials 39: 114-123, 2015.

60. Thomas NP, Li P, Fleming BC, Chen Q, Wei X, Xiao-Hua P, Li G and Wei L: Attenuation of cartilage pathogenesis in post-traumatic osteoarthritis (PTOA) in mice by blocking the stromal derived factor 1 receptor (CXCR4) with the specific inhibitor, AMD3100. J Orthop Res 33: 1071-1078, 2015.

61. Zhang W, Chen J, Tao J, Jiang Y, Hu C, Huang L, Ji J and Ouyang HW: The use of type 1 collagen scaffold containing stromal cell-derived factor-1 to create a matrix environment conducive to partial-thickness cartilage defects repair. Biomaterials 34: 713-723, 2013

62. Li L, Lv G, Wang B and Kuang L: The role of lncRNA XIST/miR-211 axis in modulating the proliferation and apoptosis of osteoarthritis chondrocytes through CXCR4 and MAPK signaling. Biochem Biophys Res Commun 503: 2555-2562, 2018

63. Zhu JK, He TD, Wei ZX and Wang YM: LncRNA FAS-AS1 promotes the degradation of extracellular matrix of cartilage in osteoarthritis. Eur Rev Med Pharmacol Sci 22: 2966-2972, 2018.

64. Takeda K, Kaisho T and Akira S: Toll-like receptors. Annu Rev Immunol 21: 335-376, 2003

65. Hausmann M, Kiessling S, Mestermann S, Webb G, Spöttl T, Andus T, Schölmerich J, Herfarth H, Ray K, Falk W and Rogler G: Toll-like receptors 2 and 4 are up-regulated during intestinal inflammation. Gastroenterology 122: 1987-2000, 2002.

66. Gomez R, Villalvilla A, Largo R, Gualillo $\mathrm{O}$ and HerreroBeaumont G: TLR4 signalling in osteoarthritis-finding targets for candidate DMOADs. Nat Rev Rheumatol 11: 159-170, 2015.

67. Wang Y, Cao L, Wang Q, Huang J and Xu S: LncRNA FOXD2-AS1 induces chondrocyte proliferation through sponging miR-27a-3p in osteoarthritis. Artif Cells Nanomed Biotechnol 47: 1241-1247, 2019.

68. Zan PF, Yao J, Wu Z, Yang Y, Hu S and Li GD: Cyclin D1 gene silencing promotes IL-1beta-induced apoptosis in rat chondrocytes. J Cell Biochem 119: 290-299, 2018.

69. Cao L, Wang Y, Wang Q and Huang J: LncRNA FOXD2-AS1 regulates chondrocyte proliferation in osteoarthritis by acting as a sponge of miR-206 to modulate CCND1 expression. Biomed Pharmacother 106: 1220-1226, 2018.

70. Hu L, Ye H, Huang G, Luo F, Liu Y, Liu Y, Yang X, Shen J, Liu Q and Zhang J: Long noncoding RNA GAS5 suppresses the migration and invasion of hepatocellular carcinoma cells via miR-21. Tumor Biol 37: 2691-2702, 2016.

71. Pickard MR and Williams GT: Molecular and cellular mechanisms of action of tumour suppressor GAS5 LncRNA. Genes (Basel) 6: 484-499, 2015.

72. Nagini S: Breast cancer: Current molecular therapeutic targets and new players. Anticancer Agents Med Chem 17: 152-163, 2017.

73. Li F, Sun J, Huang S, Su G and Pi G: LncRNA GAS5 overexpression reverses LPS-Induced inflammatory injury and apoptosis through up-regulating KLF2 expression in ATDC5 chondrocytes. Cell Physiol Biochem 45: 1241-1251, 2018 
74. Song J, Ahn C, Chun $\mathrm{CH}$ and Jin EJ: A long non-coding RNA, GAS5, plays a critical role in the regulation of miR-21 during osteoarthritis. J Orthop Res 32: 1628-1635, 2014.

75. Caramés B, Hasegawa A, Taniguchi N, Miyaki S, Blanco FJ and Lotz M: Autophagy activation by rapamycin reduces severity of experimental osteoarthritis. Ann Rheum Dis 71: 575-581, 2012.

76. Caramés B, Taniguchi N, Otsuki S, Blanco FJ and Lotz M: Autophagy is a protective mechanism in normal cartilage, and its aging-related loss is linked with cell death and osteoarthritis. Arthritis Rheum 62: 791-801, 2010.

77. Sasaki H, Kubo S, Matsumoto T, Muratsu H, Matsushita T, Ishida K, Takayama K, Oka S, Kurosaka M and Kuroda R: The influence of patella height on intra-operative soft tissue balance in posterior-stabilized total knee arthroplasty. Knee Surg Sports Traumatol Arthrosc 20: 2191-2196, 2012.

78. Wang CL, Peng JP and Chen XD: LncRNA-CIR promotes articular cartilage degeneration in osteoarthritis by regulating autophagy. Biochem Biophys Res Commun 505: 692-698, 2018.

79. Li YF, Li SH, Liu Y and Luo YT: Long noncoding RNA CIR promotes chondrocyte extracellular matrix degradation in osteoarthritis by acting as a sponge for Mir-27b. Cell Physiol Biochem 43: 602-610, 2017.

80. Zhang L, Yang C, Chen S, Wang G, Shi B, Tao X, Zhou L and Zhao J: Long noncoding RNA DANCR is a positive regulator of proliferation and chondrogenic differentiation in human synovium-derived stem cells. DNA Cell Biol 36: 136-142, 2017.

81. Zhang L, Zhang P, Sun X, Zhou L and Zhao J: Long non-coding RNA DANCR regulates proliferation and apoptosis of chondrocytes in osteoarthritis via miR-216a-5p-JAK2-STAT3 axis. Biosci Rep 38: BSR20181228, 2018.

82. Lynch KR, Thorpe SB and Santos WL: Sphingosine kinase inhibitors: A review of patent literature (2006-2015). Expert Opin Ther Pat 26: 1409-1416, 2016.

83. Marfe G, Mirone G, Shukla A and Di Stefano C: Sphingosine kinases signalling in carcinogenesis. Mini Rev Med Chem 15: 300-314, 2015

84. Fan X, Yuan J, Xie J, Pan Z, Yao X, Sun X, Zhang P and Zhang L: Long non-protein coding RNA DANCR functions as a competing endogenous RNA to regulate osteoarthritis progression via miR-577/SphK2 axis. Biochem Biophys Res Commun 500: 658-664, 2018.

85. Ishii N, Ozaki K, Sato H, Mizuno H, Susumu Saito, Takahashi A, Miyamoto Y, Ikegawa S, Kamatani N, Hori M, et al: Identification of a novel non-coding RNA, MIAT, that confers risk of myocardial infarction. J Hum Genet 51: 1087-1099, 2006.

86. Barry G, Briggs JA, Vanichkina DP, Poth EM, Beveridge NJ, Ratnu VS, Nayler SP, Nones K, Hu J, Bredy TW, et al: The long non-coding RNA Gomafu is acutely regulated in response to neuronal activation and involved in schizophrenia-associated alternative splicing. Mol Psychiatry 19: 486-494, 2014.

87. Yan B, Yao J, Liu JY, Li XM, Wang XQ, Li YJ, Tao ZF, Song YC, Chen Q and Jiang Q: IncRNA-MIAT regulates microvascular dysfunction by functioning as a competing endogenous RNA. Circ Res 116: 1143-1156, 2015.

88. Crea F, Venalainen E, Ci X, Cheng H, Pikor L, Parolia A, Xue H, Nur Saidy NR, Lin D, Lam W, et al: The role of epigenetics and long noncoding RNA MIAT in neuroendocrine prostate cancer. Epigenomics 8: 721-731, 2016.

89. Sun C, Huang L, Li Z, Leng K, Xu Y, Jiang X and Cui Y: Long non-coding RNA MIAT in development and disease: A new player in an old game. J Biomed Sci 25: 23, 2018.

90. Zhou X, Luo D, Sun H, Qi Y, Xu W, Jin X, Li C, Lin Z and Li G: MiR-132-3p regulates ADAMTS-5 expression and promotes chondrogenic differentiation of rat mesenchymal stem cells. J Cell Biochem 119: 2579-2587, 2018.

91. Liu Z, Wang H, Cai H, Hong Y, Li Y, Su D and Fan Z: Long non-coding RNA MIAT promotes growth and metastasis of colorectal cancer cells through regulation of miR-132/Derlin-1 pathway. Cancer Cell Int 18: 59, 2018

92. Li C, Pan S, Song Y, Li Y and Qu J: Silence of lncRNA MIAT protects ATDC5 cells against lipopolysaccharides challenge via up-regulating miR-132. Artif Cells Nanomed Biotechnol 47: 2521-2527, 2019

93. Zhao Y, Zhao J, Guo X, She J and Liu Y: Long non-coding RNA PVT1, a molecular sponge for miR-149, contributes aberrant metabolic dysfunction and inflammation in IL-1 $\beta$-simulated osteoarthritic chondrocytes. Biosci Rep 38: BSR20180576, 2018
94. Li Y, Li S, Luo Y, Liu Y and Yu N: LncRNA PVT1 regulates chondrocyte apoptosis in Osteoarthritis by acting as a Sponge for miR-488-3p. DNA Cell Biol 36: 571-580, 2017.

95. Jiang M, Liu J, Luo T, Chen Q, Lu M and Meng D: LncRNA PACER is down-regulated in osteoarthritis and regulates chondrocyte apoptosis and lncRNA HOTAIR expression. Biosci Rep: Jun 7, 2019 (Epub ahead of print).

96. Pei Z, Du X, Song Y, Fan L, Li F, Gao Y, Wu R, Chen Y, Li W, Zhou H, et al: Down-regulation of lncRNA CASC2 promotes cell proliferation and metastasis of bladder cancer by activation of the Wnt/ $\beta$-catenin signaling pathway. Oncotarget 8: 18145-18153, 2017

97. Liao Y, Shen L, Zhao H, Liu Q, Fu J, Guo Y, Peng R and Cheng L: LncRNA CASC2 interacts with miR-181a to modulate glioma growth and resistance to TMZ through PTEN pathway. J Cell Biochem 118: 1889-1899, 2017.

98. Huang T, Wang J, Zhou Y, Zhao Y, Hang D and Cao Y: LncRNA CASC2 is up-regulated in osteoarthritis and participates in the regulation of IL-17 expression and chondrocyte proliferation and apoptosis. Biosci Rep 39: BSR20182454, 2019.

99. Chu P, Wang Q, Wang Z and Gao C: Long non-coding RNA highly up-regulated in liver cancer protects tumor necrosis factor-alpha-induced inflammatory injury by down-regulation of microRNA-101 in ATDC5 cells. Int Immunopharmacol 72: $148-158,2019$

100. Yamamoto M, Sato S, Hemmi H, Uematsu S, Hoshino K, Kaisho T, Takeuchi O, Takeda K and Akira S: TRAM is specifically involved in the Toll-like receptor 4-mediated MyD88-independent signaling pathway. Nat Immunol 4: 1144-1150, 2003.

101. Ying H, Wang Y, Gao Z and Zhang Q: Long non-coding RNA activated by transforming growth factor beta alleviates lipopolysaccharide-induced inflammatory injury via regulating microRNA-223 in ATDC5 cells. Int Immunopharmacol 69: 313-320, 2019.

102. Tang LP, Ding JB, Liu ZH and Zhou GJ: LncRNA TUG 1promotes osteoarthritis-induced degradation of chondrocyte extracellular matrix via miR-195/MMP-13 axis. Eur Rev Med Pharmacol Sci 22: 8574-8581, 2018

103. Meyerovich K, Violato NM, Fukaya M, Dirix V, Pachera N, Marselli L, Marchetti P, Strasser A, Eizirik DL and Cardozo AK: MCL-1 is a key antiapoptotic protein in human and rodent pancreatic beta-cells. Diabetes 66: 2446-2458, 2017.

104. Li X, Yu M, Chen L, Sun T, Wang H, Zhao L and Zhao Q: LncRNA PMS2L2 protects ATDC5 chondrocytes against lipopolysaccharide-induced inflammatory injury by sponging miR-203. Life Sci 217: 283-292, 2019.

105. Collange O, Charles AL, Bouitbir J, Chenard MP, Zoll J, Diemunsch P, Thaveau F, Chakfé N, Piquard F and Geny B: Methylene blue protects liver oxidative capacity after gut ischaemia-reperfusion in the rat. Eur J Vasc Endovasc Surg 45: $168-175,2013$

106. Zheng J and Li Q: Methylene blue regulates inflammatory response in osteoarthritis by noncoding long chain RNA CILinc02. J Cell Biochem 120: 3331-3338, 2019.

107. Li Z, Chao TC, Chang KY, Lin N, Patil VS, Shimizu C, Head SR, Burns JC and Rana TM: The long noncoding RNA THRIL regulates TNF $\alpha$ expression through its interaction with hnRNPL. Proc Natl Acad Sci USA 111: 1002-1007, 2014

108. Liu G, Wang Y, Zhang M and Zhang Q: Long non-coding RNA THRIL promotes LPS-induced inflammatory injury by down-regulating microRNA-125b in ATDC5 cells. Int Immunopharmacol 66: 354-361, 2019.

109. Xiang S, Li Z, Bian Y and Weng X: Identification of changed expression of mRNAs and lncRNAs in osteoarthritic synovium by RNA-sequencing. Gene 685: 55-61, 2019.

110. Zhao Y and Xu J: Synovial fluid-derived exosomal lncRNA PCGEM1 as biomarker for the different stages of osteoarthritis. Int Orthop 42: 2865-2872, 2018.

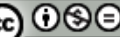

This work is licensed under a Creative Commons Attribution-NonCommercial-NoDerivatives 4.0 International (CC BY-NC-ND 4.0) License. 